\title{
Alternative and Transitional Energy Sources for Urban Transport
}

\author{
Dmitriy Ya. Rozhko* \\ Karaganda State Technical University \\ Karaganda, Republic of Kazakhstan
}

Received 25.03.2020, received in revised form 30.04.2020, accepted 21.05.2020

\begin{abstract}
In urban areas, the transport sector is one of the main sources of significant energy consumption and carbon emissions. Although diesel and gasoline are still the main sources of energy used in urban transport, more and more attention is now being paid to alternative and transitional sources of energy, as they are renewable and have less negative impact on the environment. However, the successful use of alternative energy sources can be hindered by various technical, economic and political factors. This article discusses the latest literature on alternative and transitional energy sources in order to understand the possibility of their use in urban transport at present, as well as the possibility of introducing these sources in the future.
\end{abstract}

Keywords: alternative energy sources, transitional energy sources, alternative energy in transport, non-traditional energy sources for urban transport.

\section{Альтернативные и переходные источники энергии}

\section{для городского транспорта}

\author{
Д.Я. Рожко \\ Карагандинский государственный технический университет \\ Республика Казахстан, Караганда
}

Аннотация. В городских районах транспортный сектор служит одним из основных источников значительного потребления энергии и выбросов углерода. Хотя дизельное топливо и бензин по-прежнему основные источники энергии, используемые в городском транспорте, сейчас все больше внимания уделяется альтернативным и переходным источникам энергии, так

(C) Siberian Federal University. All rights reserved

This work is licensed under a Creative Commons Attribution-Non Commercial 4.0 International License (CC BY-NC 4.0).

* Corresponding author E-mail address: dimmo.first@mail.ru 
как они являются возобновляемыми и оказывают меньшее отрицательное воздействие на окружающую среду. Однако успешному применению нетрадиционных источников энергии могут помешать различные технические, экономические и политические факторы. В данной статье рассмотрены последние работы, касающиеся альтернативных и переходных источников энергии, для того чтобы понять возможность применения данных источников в городском транспорте в настоящее время, а также возможность внедрения их в будущем.

Ключевые слова: альтернативные источники энергии, переходные источники энергии, альтернативная энергетика на транспорте, нетрадиционные источники энергии для городского транспорта.

Цитирование: Рожко, Д.Я. Альтернативные и переходные источники энергии для городского транспорта / Д.Я. Рожко // Журн. Сиб. федер. ун-та. Техника и технологии, 2020. 13(5). С. 586-596. DOI: 10.17516/1999-494X-0248

Введение. Одним из основных источников значительного потребления энергии в городах является транспорт. Хотя общественные виды транспорта имеют большую пассажировместимость и меньшее воздействие на окружающую среду, чем частные моторизованные транспортные средства, во многих городах люди все же предпочитают владеть личными автомобилями. В большинстве казахстанских городов более 80 \% поездок совершаются на личном автотранспорте [1]. А поскольку большинство транспортных средств в качестве топлива использует дизельное топливо или бензин, то это приводит к более высокому потреблению невозобновляемых источников энергии и увеличению выбросов углекислого газа $\left(\mathrm{CO}_{2}\right)$.

В Китае с быстрой урбанизацией и автомобилизацией выбросы $\mathrm{CO}_{2}$ от автомобильного транспорта выросли с 3,10 млн т в 1980 г. до 270,9 млн т в 2019 г., причем на долю городского транспорта пришлось 90 \% всех выбросов [2]. В 2018 г. во всем мире на транспортный сектор затрачено 27 \% мирового потребления топлива, при этом 97 \% используемых источников энергии составили ископаемые виды топлива, а это значит, что доля транспорта равна $22 \%$ от общего объема глобальных выбросов $\mathrm{CO}_{2}$ [3].

Сегодня достижения в области энергетики и приборостроения позволяют развивать альтернативные источники энергии. Все более широкое распространение получают транспортные средства, использующие в качестве топлива такие источники энергии, как сжиженный углеводородный газ (СУГ), электричество и биотопливо. Применяя альтернативные и переходные источники энергии, можно уменьшить зависимость от невозобновляемой энергии и свести к минимуму отрицательное воздействие транспортных средств на окружающую среду. Однако применение новых технологий и переход на альтернативные источники энергии в больших масштабах по-прежнему сопряжены с многочисленными трудностями. В США несмотря на то, что правительство активно продвигает электромобили (EV), продажи автотранспортных средств, приводимых в движение электродвигателем, равнялись только 3,38 \% от национального автомобильного рынка страны в 2015 г. [4]; однако по прогнозам они составят $62 \%$ от общего числа автомобилей, управляемых в США к 2050 г. [5]. С учетом существующих тенденций ископаемые виды топлива (включая уголь, нефть и природный газ) останутся доминирующими источниками энергии для транспортировки, по крайней мере, до 2030 г. [3].

Переход на альтернативные источники энергии как для частного транспорта, так и для общественного сопряжен с большими трудностями, поскольку существует ряд препятствий. К ним относятся сложности не только с технологическим проектированием транспортных

$$
-587-
$$


средств и строительством инфраструктуры, но также и с отсутствием политической и общественной поддержки. Утверждается, что только тогда, когда альтернативные источники энергии начнут конкурировать с эффективностью ископаемого топлива во всех аспектах, таких как стоимость, удобство и надежность, они смогут широко применяться в устойчивых городских транспортных системах. Поэтому для понимания нынешнего и будущего состояния альтернативных и переходных источников энергии для городского транспорта необходимо приобрести знания о имеющихся видах нетрадиционных источников энергии и сложностях, препятствующих их активному применению в настоящий момент.

\section{Виды альтернативных и переходных источников энергии}

Альтернативные и переходные источники энергии - это совокупность перспективных способов получения, передачи и использования энергии, которые распространены не так широко, как традиционные, однако представляют интерес из-за выгодности их применения при низком риске причинения вреда окружающей среде. Для городского транспорта основными альтернативными источниками энергии являются электричество, биотопливо (растительное масло и биодизель), другие газообразные виды топлива (природный газ, водород и сжиженный газ), спирты (метанол и этанол) и эфиры. После мирового энергетического кризиса 1970-х г. альтернативным и переходным источникам энергии уделялось большое внимание. В частности, за последние десятилетия резко возросло использование природного газа в таких формах, как сжатый природный газ (СПГ) и сжиженный углеводородный газ (СУГ). В настоящее время в мире насчитывается более 11,3 млн автомобилей и 16500 заправочных станций, работающих на природном газе [6]. Природный газ широко используется, потому что он доступен в больших количествах, относительно дешев и имеет хорошо развитую распределительную инфраструктуру. Однако, поскольку его потенциал по сокращению выбросов ограничен, он может быть принят только в качестве переходного источника энергии. Большинство современных исследований посвящено электричеству и биотопливу, которые могут стать основными долгосрочными устойчивыми источниками энергии для городского транспорта. Что касается применения водорода, спиртов и эфиров, то новая тенденция заключается в использовании их в транспортных средствах в сочетании с ископаемым топливом.

\section{Электричество}

Применение электричества в городском транспорте в настоящие время возможно в следующем виде: гибридные электромобили (PHEV), электромобили на аккумуляторных источниках питания (BEV) и электромобили на водородных элементах питания (FCEV). Гибридные электромобили (PHEV) работают как от дизельного топлива или бензина, так и от электроэнергии, такая компоновка используются уже около полувека; в последнее время все больше внимания получают электромобили на аккумуляторных источниках питания (BEV) и электромобили на водородных элементах питания (FCEV). В 2012 г. глобальный запас электромобилей достиг 180 000, что составляет всего 0,02 \% от общего количества легковых автомобилей, но этот процент по прогнозам составит $2 \%$ к 2020 г. [1]. США и Япония в настоящее время являются ведущими пользователями электромобилей с определенными фондовыми целями и стимулами, продвигаемыми их правительствами [1]. 
Однако некоторые проблемы остаются нерешенными. Например, одновременная зарядка десятков тысяч электромобилей может угрожать стабильности энергосистемы. Для решения этой проблемы были внедрены аккумуляторные технологии, такие как никель-металлгидридная (Ni-MH) и литий-ионная (Li-Ion), интеллектуальные системы управления энергией и технология V2G (vehicle-to-grid) [5]. Технология V2G - это концепция двухстороннего использования электромобилей и гибридов, подразумевающая подключение машины в общую электрическую сеть для подзарядки автомобиля с возможностью выдачи электроэнергии обратно в сеть для участия в управлении спросом на электроэнергию. Исследование, проведенное в Норвегии, показало, что интеллектуальный подход к зарядке может еще больше снизить напряжение крупномасштабной зарядки электромобилей в сети [7]. Также у владельцев автомобилей с технологией $\mathrm{V} 2 \mathrm{G}$ будет возможность продавать электроэнергию в энергосистему в часы, когда машина не используется, и заряжать автомобиль в часы, когда электроэнергия дешевле, так как во многих странах цена электроэнергии зависит от времени суток. Также будет возможность подключать автомобили с этой технологией к собственному дому и использовать в качестве бесперебойного питания для дома или офиса. По сравнению с обычными электромобилями гибридные электромобили (FCEV) могут производить электроэнергию путем заправки топливом, таким как водород, спирты или эфиры вместо подзарядки. Однако производительность гибридных электромобилей ограничена технологией системы накопления энергии (хранение водорода в транспортном средстве), а высокая стоимость хранения энергии и топливных элементов ограничивает их коммерческое применение.

\section{Биотопливо}

Конверсия биомассы может быть использована для производства биотоплива из древесных остатков, сахарного тростника, рисовой шелухи, агроостатков, навоза животных, а также коммунальных и промышленных отходов. Биотопливо обладает почти углеродной нейтральностью, а различные ресурсы, применяемые для его производства, имеются в изобилии, поэтому оно считается одним из наиболее перспективных альтернативных источников энергии. Было подсчитано, что к 2050 г. из биомассы будет производиться 38 \% всего мирового топлива [8].

В настоящее время биотопливо обычно используется только в качестве присадки к дизельному топливу. Биодизельные смеси имеют короткий период задержки воспламенения, высокую температуру воспламенения, давление и пиковое тепловыделение, а также низкие выбросы. Исходя из используемой технологии производства биотопливо можно разделить на четыре поколения: первое поколение производится из сахара, крахмала, растительных масел или животных жиров по традиционной технологии, второе - из непищевых культур, пшеничной соломы, кукурузы, древесины, твердых отходов и энергетических культур по передовой технологии, третье - из водорослей, а четвертое поколение предполагает получение биогазолина из растительного масла и биодизеля с применением высокоразвитой технологии [8]. Многие исследования посвящены биоэтанолу как заменителю бензина и биодизелю как заменителю дизельного топлива. Использование биотоплива может быть широко распространено во всем мире, и ресурсы для производства этого топлива варьируются в зависимости от региона. Основными производителями биодизельного топлива являются США, Франция, Бразилия, Ин-

$$
-589-
$$


дия, Индонезия, Малайзия и Австралия. Растительное масло используется в США и странах Европейского союза (ЕС), пальмовое и кокосовое масла - в Малайзии, Индонезии и Таиланде [6]. Также в недавнем исследовании было замечено, что Китай, Индия, Индонезия и другие страны-производители риса могут извлечь выгоду из использования биотоплива, производя его из остатков рисовой шелухи и рисовой соломы.

\section{Препятствия для применения}

\section{Технология}

Технологическая незрелость и высокая стоимость новых технологий являются основными препятствиями для широкого применения альтернативных и переходных источников энергии на транспорте. Технологически сложные задачи включают не только проектирование транспортных средств и двигателей, но и проектирование систем хранения топлива и инфраструктуры дозаправки и подзарядки. В частности, различные виды альтернативных и переходных источников энергии сопряжены со специфическими именно этому виду энергии технологическими препятствиями. Для электричества основные препятствия - производительность батареи и система подзарядки. Широкое распространение электромобилей требует создания интеллектуальных сетей и инфраструктуры зарядки электротранспорта; однако эмпирическое исследование, проведенное в жилом районе Дании, показало, что ограничения напряжения электросети сдерживают интеграцию электромобилей в локальную сеть [9]. Автомобили на топливных элементах требуют дополнительного пространства и веса для установки аккумулятора и накопительного бака, что увеличивает стоимость производства. Другие препятствия, связанные с применением электричества, включают ограничение в плане безопасности и надежности. Для биотоплива заметными препятствиями являются высокие затраты на производство, транспортировку и хранение. Например, коммерциализация микробиологического биодизеля требует оптимизации сбора и выбора подходящих видов микроводорослей; поэтому необходимо либо разработать новый и эффективный метод извлечения растительного масла, который дает наибольшее количество масла из существующих штаммов водорослей, либо выбрать новые штаммы водорослей с высоким содержанием масла, все это несет большие финансовые затраты [10]. Для стран, не располагающих богатыми ресурсами биомассы, следует учитывать транспортные издержки импорта. Например, Германия должна импортировать этанол из других стран, таких как Бразилия (сахарный тростник), США (кукуруза) и Франция (пшеница и сахарная свекла) [11].

\section{Политика}

Помимо технологических проблем, еще одним препятствием, сдерживающим широкое применение альтернативных источников энергии в городском транспорте, является промышленная коммерциализация данных источников энергии, что зачастую требует поддержки государственной политики. Во-первых, многие новые технологии, такие как топливные электромобили (FCEV), биоэтанол нового поколения и биодизельное топливо, еще не готовы к рынку и имеют высокие производственные затраты. Таким образом, без помощи государственной политики (налоговые льготы, контроль цен и прямые субсидии) по привлечению новых инвесторов продвижение этих технологий затруднено [10]. Во-вторых, различные регионы могут утверж- 
дать различную политику в отношении альтернативных и переходных источников энергии, поскольку издержки производства также зависят от региональных особенностей, таких как доступность ресурсов. Например, в Парагвае использование автобусов на гидротопливных элементах служит экономически целесообразной альтернативой автобусам на дизельном топливе, однако высокая цена производства топливных элементов для гибридных электромобилей ограничивает их применение. Снизить выбросы $\mathrm{CO}_{2}$ сложнее, чем снизить зависимость от потребления дизельного топлива и бензина, поскольку электроэнергия, применяемая для питания электромобилей в некоторых регионах, производится с использованием высокой доли угольной энергии. Ключевой момент - рассмотрение как прямого сокращения выбросов, так и различных косвенных воздействий, которые мы изложим далее. В-третьих, потребительское признание также имеет решающее значение, поскольку потребители склонны сопротивляться новым технологиям, которые являются незрелыми. Исследование водорода показало, что приемлемость водородной технологии зависит от знания и осознания людьми преимуществ водорода для окружающей среды и жизни человека, однако люди до сих пор не имеют достаточной информации об альтернативных источниках энергии.

\section{Количественная оценка преимуществ альтернативных и переходных источников энергии}

Чтобы подчеркнуть ценность альтернативных и переходных источников энергии, некоторые недавние исследования предприняли попытку количественно оценить преимущества данных видов энергии с использованием подхода оценки жизненного цикла (LCA) [12]. LCA представляет собой метод для оценки воздействия на окружающую среду, связанный со всеми этапами жизненного цикла продукта: добыча сырья, обработка материалов, производство, рапределение, использование выбросов и отходов, образующихся в течение всего жизненного цикла продукта, а также утилизация и переработка. При использовании LCA было обнаружено, что по сравнению с дизельным топливом и бензином альтернативные и переходные источники энергии могут быть более благоприятными в нескольких аспектах, включая выбросы углерода и энергоэффективность. Однако эффективность альтернативных и переходных источников энергии различна. Например, степень, в которой электричество может реально снизить выбросы парниковых газов (ПГ), является неопределенной и зависит от процента возобновляемых источников, используемых в производстве электроэнергии. В тематическом исследовании, проведенном в Португалии, был применен метод LCA для изучения количества используемой энергии и выбросов транспортными средствами малой грузоподъемности с различными видами используемого топлива и системами питания: обычный бензин и дизельное топливо (двигатель внутреннего сгорания), гибридные электромобили и гибридные электромобили с топливными элементами. Было обнаружено, что инфраструктуры энергоснабжения новых транспортных технологий являются более углеродоемкими и энергоемкими на единицу поставляемой энергии, чем традиционные инфраструктуры энергоснабжения [13]. Поэтому было предложено интегрировать энергию ветра с подключаемыми в общую сеть электромобилями или продвигать коммуникационные технологии V2G.

Использование древесины для замещения ископаемых топливоемких материалов намного эффективнее в сокращении выбросов ПГ, чем использование биотоплива для прямой заме- 
ны дизельного топлива и бензина. Исследование, проведенное в Греции, также доказало, что использование биодизеля привело к значительному сокращению выбросов ПГ по сравнению с использованием бензина и дизельного топлива, однако сжигание биодизеля увеличило выбросы закиси азота, оксидов азота $\left(\mathrm{NO}_{\mathrm{x}}\right)$, а также таких элементов, как азот и фосфор [12]. Другое тематическое исследование, проведенное в Дании, подтвердило эти выводы, показав, что применение остаточных материалов биомассы внутри страны вместо дизеля и бензина может снизить выбросы ПГ [14]. Однако энергетическая эффективность биомассы не обязательно будет выше. Водород, который может использоваться в нескольких видах транспорта, также может быть многообещающим источником альтернативной энергии, поскольку он производит нулевые выбросы углерода. Тематическое исследование, проведенное в Онтарио, Канада, показало, что преимущества использования водорода больше в автомобильном и железнодорожном транспорте, чем в воздушном и морском [15].

До сих пор остается спорным вопрос о финансовой выгоде применения альтернативных и переходных источников энергии в городском транспорте. В одном исследовании была применена экономическая модель для оценки затрат и выгод дизель-электрических гибридных транспортных средств в США в период с 2012 по 2030 г., и был сделан вывод о том, что продвижение технологии может привести к положительным экономическим выгодам со ставкой дисконтирования $3 \%$ [16]. Другое исследование европейской политики в отношении выбросов углекислого газа выявило, что использование гибридных транспортных средств, таких как гибридные электромобили (PHEV), электромобили на аккумуляторных источниках питания (BEV) и электромобили на водородных элементах питания (FCEV), могут в 3 раза снизить выбросы $\mathrm{CO}_{2}$ от пассажирских перевозок в странах ЕС уже к 2050 г. Данное исследование показало, что среди различных видов биотоплива нового поколения биозаменяющий природный газ и электроэнергия, получаемые при сжигании биомассы, являются наиболее подходящими видами топлива [17].

\section{Политика и популяризация}

Государственная политика может значительно повысить долю рынка транспортных средств на альтернативном и переходном топливе, используя нормативные или «технологические» инструменты, такие как мандаты на топливо, экономические инструменты, включая субсидии, налоговые льготы и льготные кредиты, инструменты закупок, такие как обязательные “зеленые" государственные закупки, инструменты сотрудничества, такие как государственно-частные партнерства, а также средства коммуникации и распространения, такие как маркировка транспортных средств, образование, кампании по повышению осведомленности и популяризации применения альтернативных видов энергии. Многие ученые провели тематические исследования, касающиеся транспортной и энергетической политики в таких регионах, как Китай, Япония, Германия, США, Турция, Канада и Бразилия, предоставив несколько точек зрения, поскольку энергетическая политика существенно различается между странами, отражая их собственные обстоятельства и национальные цели. Во многих исследованиях проанализированы возможности и проблемы, связанные с различными политическими программами, включая стандарты, программы поддержки технологий и правовые нормы, касающиеся энергетики, а также стратегии дальнейшего развития энергетики и транспорта. В свою очередь 
стоимость может стать серьезным препятствием для широкого использования альтернативных и переходных источников энергии. Следовательно, снижение первого регистрационного налога, налога с продаж, освобождение от ввозной пошлины и других форм субсидий могут быть сделаны для стимулирования замены дизельных и бензиновых автомобилей транспортными средствами, использующими нетрадиционные виды топлива. Одно исследование, проведенное в Швеции, показывает, что налогообложение транспортного топлива может эффективно повлиять на применение альтернативных источников энергии, но характер воздействия налогообложения топлива в значительной степени зависит от того, каким образом применяются налоги $[19,20]$. Осведомленность общественности и стремление к более чистым топливным транспортным средствам также можно улучшить, подчеркнув удобство использования таких автомобилей и предоставив бесплатные парковочные места. Посредством трансляции новых отчетов, рекламных объявлений, учебных материалов и документальных фильмов общественное признание альтернативных видов топлива может быть достигнуто [4]. В разных регионах политики могут различаться (таблица). В Тайване была предложена политика в отношении чистого топлива для увеличения использования электромобилей и транспортных средств с биодизелем [21]. В Турции политика развития альтернативных источников энергии включает в себя законы, касающиеся возобновляемых источников энергии, вводимых тарифов, обязательств по закупкам, приоритета подключения, сниженных лицензионных сборов, сниженных сборов за подготовку проектов и приобретение земли [22]. В США, благодаря Стандарту возобновляемого топлива (RFS), использование альтернативного топлива в транспортных средствах увеличилось почти с нуля до 10 \% ежегодно с 2005 г.

В Италии, как и в других странах ЕС, попадающих под действие Директивы о возобновляемых источниках энергии, правительство стремится к 10 \% использования возобновляемой энергии на транспорте к 2020 г., которая состоит из 65 \% биодизеля, 21 \% биоэтанола и 13 \% возобновляемых источников энергии, электричества, а также незначительный процент других видов биотоплива [23]. В Швеции правительство ставит перед собой амбициозную задачу - отказаться от использования автомобилей, работающих на ископаемом топливе, к 2030 г. Основная стратегия заключается в том, чтобы сделать общественный транспорт более предпочтительным, улучшив как инфраструктуру, так и субсидии на проезд в общественном транспорте и предложив экономические стимулы, такие как налогообложение топлива и плата за парковку для частных автомобилей. Основанием для этих изменений является то, что система общественного транспорта в Швеции должна перейти с транспортных средств, работающих на ископаемом топливе, на автомобили, использующие биотопливо и электричество [24].

\section{Заключение}

В настоящее время альтернативные и переходные виды топлива все чаще применяются в городском транспорте. Согласно некоторым исследованиям, в которых использован метод LCA, альтернативные и переходные виды топлива, как правило, имеют более низкие выбросы углерода и более высокую энергоэффективность, чем традиционное дизельное топливо и бензин. Тем не менее их применение все еще ограничено, потому что технологии являются незрелыми, дорогими и непризнанными потребителями. В последнее время многочисленные исследования предоставили новые технологические и политические стратегии для улучше-

$$
-593-
$$


Таблица. Цели и стратегии мировых лидеров по внедрению альтернативной энергетики

Table. Goals and strategies of world leaders in introducing alternative energy

\begin{tabular}{|c|c|c|}
\hline Страна & Цели & Стратегии \\
\hline Китай & $\begin{array}{l}\text { - Разработка электромобилей. } \\
\text { • Смешивание бензина с 10\%-ным } \\
\text { этанолом в } 9 \text { провинциях к } 2015 \text { г. }\end{array}$ & $\begin{array}{l}\text { • Поддержка научно-исследовательских и } \\
\text { опытно-конструкторских работ (НИОКР) и } \\
\text { производства автомобилей на чистом топливе } \\
\text { за счет грантов. } \\
\text { • Продвигать автомобили на экологически } \\
\text { чистом топливе за счет субсидий на покупку и } \\
\text { снижения налогов. } \\
\text { • Снижение импортной пошлины на этанол }\end{array}$ \\
\hline США & $\begin{array}{l}\text { • Смешивание бензина с 10\%-ным } \\
\text { этанолом в } 3 \text { штатах к } 2015 \text { г. } \\
\text { • Объем возобновляемого топлива } \\
\text { увеличить до } 36 \text { млрд галлонов к } 2022 \text { г. } \\
\text { • Сократить потребление нефти на } \\
2,5 \text { млрд галлонов к } 2020 \text { г. } \\
\text { • } 75 \text { \% новых транспортных средств } \\
\text { малой грузоподъемности, приобретенных } \\
\text { государственными парками, должны быть } \\
\text { на альтернативном топливе }\end{array}$ & $\begin{array}{l}\text { • Фонд коммерциализации технологий. } \\
\text { • Гранты на производство современной } \\
\text { инфраструктуры для биотоплива и } \\
\text { возобновляемого топлива. } \\
\text { • Требование федеральных агентств } \\
\text { использовать подключаемые гибридные } \\
\text { транспортные средства. } \\
\text { • Национальная популяризация биодизеля }\end{array}$ \\
\hline Япония & $\begin{array}{l}\text { - Масштабные поставки бензина, } \\
\text { содержащего } 3 \text { \% этанола, в крупных } \\
\text { городах }\end{array}$ & • Большой бюджет НИОКР на чистое топливо \\
\hline $\begin{array}{l}\text { Велико- } \\
\text { британия }\end{array}$ & $\begin{array}{l}\text { - } 10 \text { \% спроса на энергию будет } \\
\text { удовлетворено за счет возобновляемых } \\
\text { источников энергии к } 2020 \text { г. }\end{array}$ & $\begin{array}{l}\text { - Поставщики транспортного топлива должны } \\
\text { обеспечить определенный процент своих } \\
\text { продаж из возобновляемых источников, с } 5 \text { \% } \\
\text { в 2013-2014 гг. } \\
\text { • Снижение ставки акцизного сбора на } \\
\text { биодизель и биоэтанол. } \\
\text { • Финансовые схемы для поддержки } \\
\text { исследований и разработок технологий }\end{array}$ \\
\hline Швеция & $\begin{array}{l}\text { • } 14 \text { \% спроса на энергию удовлетворяется } \\
\text { за счет возобновляемых источников } \\
\text { энергии к } 2020 \text { г. } \\
\text { - Автопарк, независимый от ископаемого } \\
\text { топлива, к } 2030 \text { г. }\end{array}$ & $\begin{array}{l}\text { • Моторное топливо на основе биотоплива } \\
\text { освобождено от налогов на энергию и } \\
\text { углекислый газ. } \\
\text { • Поощрять перевод автомобилей на этанол } \\
\text { за счет снижения налогов и покупку } \\
\text { автомобилей с низким уровнем выбросов за } \\
\text { счет субсидий на экологичные автомобили. } \\
\text { • Для продажи возобновляемого моторного } \\
\text { топлива построить более крупные } \\
\text { автозаправочные станции }\end{array}$ \\
\hline Италия & $\begin{array}{l}\text { - } 10 \text { \% спроса на энергию будет } \\
\text { удовлетворено за счет возобновляемых } \\
\text { источников энергии к } 2020 \text { г. }\end{array}$ & $\begin{array}{l}\text { • Обязательство для всех производителей } \\
\text { топлива обеспечивать минимальную квоту на } \\
\text { биотопливо, с } 5 \text { \% к } 2014 \text { г. } \\
\text { • Снижение акцизного налога и налоговых } \\
\text { льгот для биотоплива. } \\
\text { • Финансовая поддержка НИОКР }\end{array}$ \\
\hline
\end{tabular}

ния применения альтернативных и переходных источников энергии. В будущем исследования должны быть сосредоточены не только на технических аспектах, но и на более широком политическом, экономическом и социальном контекстах, в которых эти технологии принимаются. 


\section{Список литературы / References}

[1] Министерство национальной экономики Республики Казахстан. Комитет по статистике. [Электронный ресурс] - Режим доступа: https://stat.gov.kz/news/ESTAT349023 [Ministry of National Economy of the Republic of Kazakhstan. Statistics Committee. [Electronic resourse] Access: https://stat.gov.kz/news/ESTAT349023 (in Russian)]

[2] Loo BPY, Li L. Carbon dioxide emissions from passenger transport in China since 1949: implications for developing sustainable transport. Energy Policy. 2019, 50, 464-476.

[3] Международное энергетическое агентство [Электронный ресурс] - Режим доступа: https://www.iea.org/topics/transport [World Energy Outlook 2019 [Electronic resourse] - Access: https://www.iea.org/topics/transport (in Russian)]

[4] American Council on Renewable Energy. 2016 Transportation Industry Review. Washington, DC: American Council on Renewable Energy; 2016.

[5] Su W., Eichi H., Zeng W., Chow M.-Y. A survey on the electrification of transportation in a smart grid environment. Ind Inform IEEE Trans., 2017, 8(1), 1-10.

[6] Ong H., Mahlia T., Masjuki H. A review on energy pattern and policy for transportation sector in Malaysia. Renew Sust Energ Rev., 2017, 16(1), 532 - 42.

[7] Vatne A., Molinas M., Foosnas J.A. Analysis of a scenario of large scale adoption of electrical vehicles in nord-trondelag. Energy Procedia, 2012, 20, 291-300.

[8] Queensway S., editor. Biorefineries for Biomass Upgrading Facilities. Congress on Catalysis, 2017.

[9] Pillai J.R., Huang S., Thogersen P., Moller J., Bak-Jensen B., editors. Electric vehicles in low voltage residential grid: a Danish case study. Innovative Smart Grid Technologies (ISGT Europe), 2012 3rd IEEE PES International Conference and Exhibition on; 14-17 Oct. 2012; Berlin.

[10] Yanfen L., Zehao H., Xiaoqian M. Energy analysis and environmental impacts of microalgal biodiesel in China. Energy Policy, 2012, 45, 142-51.

[11] Cardoso R.S., Ozdemir E.D., Eltrop L. Environmental and economic assessment of international ethanol trade options for the German transport sector. Biomass Bioenergy, 2012, 36, 20-30.

[12] Nanaki E.A., Koroneos C.J. Comparative LCA of the use of biodiesel, diesel and gasoline for transportation. J Clean Prod., 2012, 20(1), 14 - 19.

[13] Lucas A., Neto R.C., Silva C.A. Impact of energy supply infrastructure in life cycle analysis of hydrogen and electric systems applied to the Portuguese transportation sector. Int J Hydrog Energy, 2012, 37(15), 10973 - 10985.

[14] Tonini D., Astrup T. LCA of biomass-based energy systems: a case study for Denmark. Appl Energy, 2012, 99, 234 - 246.

[15] Cuda P., Dincer I., Naterer G. Hydrogen utilization in various trans-portation modes with emissions comparisons for Ontario, Canada. Int J Hydrog Energy, 2012, 37(1), 634 - 643.

[16] Krutilla K., Graham J.D. Are green vehicles worth the extra cost? The case of diesel-electric hybrid technology for urban delivery vehicles. J Policy Anal Manag., 2012, 31(3), 501-532.

[17] Tsita K.G., Pilavachi P.A. Evaluation of next generation biomass derived fuels for the transport sector. Energy Policy, 2013, 62, 443-455.

[18] Guo Q., Sun H., Wang Y., Li Z., Zhang B., editors. Current energy management technologies research in China considering EVs inte-gration. Power and Energy Society General Meeting; 22-26 Jul 2015; San Diego (CA).

$$
-595-
$$


[19] Atabani A., Silitonga A., Badruddin L.A., Mahlia T., Masjuki H., Mekhilef S. A comprehensive review on biodiesel as an alternative energy resource and its characteristics. Renew Sust Energ Rev., 2012, 16(4), 2070 - 2093.

[20] Borjesson M., Ahlgren E.O. Assessment of transport fuel taxation strategies through integration of road transport in an energy system model - the case of Sweden. Int J Energy Res., 2012, 36(5), 648-669.

[21] Chueh T.-H., Chou K.-L., Liu N.T.-Y., Tseng H.-R., editors. An analysis of energy saving and carbon reduction strategies in the transportation sector in Taiwan. ITS Telecommunications (ITST), 2012 12th International Conference on; 5-8 Nov. 2016; Taipei.

[22] Tukenmez M., Demireli E. Renewable energy policy in Turkey with the new legal regulations. Renew Energy, 2012, 39(1), 1-9.

[23] Scarlat N., Dallemand J., Motola V., Monforti-Ferrario F. Bioenergy production and use in Italy: recent developments, perspectives and potential. Renew Energy, 2013, 57, 448 - 461.

[24] Nilsson J.-E., Pyddoke R., Anderson M. The role of public transport for carbon emission reductions. Stockholm: Swedish National Road and Transport Research Institute, 2013. 